\title{
Farmer perspectives on sustainable farming
}

\author{
J.H. COTMAN \\ Waikato Federated Farmers, PO Box 447, Hamilton
}

\begin{abstract}
Waikato Federated Farmers has recently taken a proactive role in land management issues which has involved developing for farmers an operational definition of sustainable farming and ways of promoting and demonstrating sustainable practices on farm. In partnership with AgResearch and Environment Waikato, the operational definition, management practices and user friendly indicators to aid monitoring were obtained, Sustainable farming recognises socio-economic goals of farmers (viable business, enjoyable lifestyle, good living standards, good short term profitability, satisfied farmers) and resource goals (efficient, contented animals, productive pasture, clean water, control of feral pests, unrestricted market access, adequate rural services, family heath). Grazing guidelines have been produced using the above information and on-farm study groups set up to demonstrate these practices in a whole-farm system. Userfriendly indicators have also been developed and are in use.
\end{abstract}

Keywords: farming goals, guidelines, participatory process, sustainable farming

\section{Introduction}

"Sustainable Farming" is one of the buzzwords of the nineties!

Is sustainable farming a threat or indeed an opportunity for New Zealand?

Federated Farmers picked up the challenge and set out to document current information so as to assemble some facts to stimulate debate.

As a first step, to reach some conclusion, our focus needed to be upon ourselves, as farmers who indeed have the responsibility of long-term stewardship of our land.

The impetus to start was increased when Environment Waikato attempted to present a land use module for its Transitional Regional Plan. This challenged land owners over fundamental environmental management but focused too narrowly on a land classification system. This system allowed arbitrary judgement to be passed without considering a range of variable factors that might otherwise influence land use.

It was determined that we needed to take a proactive role in land management issues and look for ways of promoting sustainable farming practices. Thus we aimed at publishing a guide of management practices that could promote good environmental outcomes, while ensuring farming remained relatively profitable and enjoyable.

We based the project on the following key criteria:

- That land owners are responsible for minimising effects on the environment.

- That market access, international and local, will be tied to the market's perception of our sustainable farming practices.

- That the operational definition of sustainable practices should come from farmers.

- That partnerships would be sought with research groups to develop economically viable practices.

\section{Stage 1}

Federated Farmers set about defining sustainable farming by undertaking the following steps:

A partnership approach with AgResearch, Whatawhata, was developed to implement our goals, and Environment Waikato was also invited to participate. The process used was a problem-solving concept (Parminter et al. 1993).

A series of workshops were held with farming groups - up to 100 participants with a single goal - to develop for farmers an operational definition of "sustainability".

\section{Workshop results:}

- Sustainable farming would recognise the socioeconomic goals of farmers such as:

- viable farming business

- enjoyable lifestyle

- good living standards

- good short-term profitability

- satisfied (financially secure) farmers

Farmers would achieve these goals through seeing to the following: 
- efficient, contented, animals

- productive pasture

- clean water

- unrestricted market access

- farmer and farm family health

- adequate rural and agricultural services

- control of feral pests

A clear message came through that farmers' economic viability was paramount, but they did have a long-term view viz: to manage the resource (the farm) wisely for the benefit of future generations. Similar results were obtained from farmer workshops held in Hawke's Bay by Hawke's Bay Regional Council (Grey 1995).

We now had a set of farmer-recognised goals that could be judged through a few key areas that led to sustainable farming.

From the overall concept of sustainability as above, farmers further defined through a series of objectives, how these would be achieved and monitored. For example, farmers recognised that to achieve sustainable enterprises, they required both:

(a) Efficient, contented animals. This would be achieved through managing such factors as:

* animal health

stocking rates

animal shelter

stock performance

stock enterprise

(b) Productive pasture. This would be achieved through managing such factors as:

* high producing pasture

vigorous pasture

* quality pasture

* fertile soils

well-structured soils

Farmers were then encouraged to build upon these concepts and to define, in their own terms, objectives that would achieve these goals. An exhaustive list was compiled, which underlines the complex nature of farm management.

A small selection is as follows:

selecting suitable livestock enterprises

managing stocking rates

monitoring stock performance

setting optimum mob densities

establishing and using animal shelter

- management of pasture for quality

- plant genetic improvement
- planned farm subdivision

controlled water management

- maintaining a balance of soil nutrients

- best use of fertilisers

nutrient management

maintaining soil structure

avoiding chemical contamination

control of feral animals

control of weeds

A list of indicators to describe the impact of particular managements was compiled, and this suggested that farmers would primarily use visual assessment in determining outcomes of specific management practices.

Farmers would not set objective measures on their indicator descriptions, choosing instead to leave it to individual land owners to evaluate their own operations.

The following are examples of indicators used by farmers:

Not surprisingly, livestock farmers viewed the sustainability of their enterprise through their livestock indicators,

e.g. health

condition

coat

contentment

grazing preferences

moving ability

Pasture observation also figures highly as an indicator of farm health,
e.g. good clover content
dense sward
persistent pasture
few weeds
low dead matter
rich green colour

A number of base monitoring tools are already available and in use, such as the following:

- herd recording

- herd production testing

- animal health (e.g., somatic cell counts in milk and drenching schedules)

- pasture growth

- grazing records

- fertiliser records soil and herbage analysis

rainfall

- ground temperatures

- financial recording systems 
Thus, while farmers already have many indicators (or monitoring systems) at hand, the challenge will be to determine the effects of management practices on these indicators.

But we now have a basis from which to work.

The proposed Grazing Guidelines have now developed to the stage where a Resource Kit based on the farmer information has been published (Sustainable Agriculture Manual). It is unique in that the content is based entirely on farmer input and serves as a valuable stimulus for further information.

\section{Stage 2}

We are now moving forward into the next phase which involves demonstration of on-farm sustainable practices. We have used an on-farm study group concept as a focal point for enabling farmer participants to plan, implement, monitor and interpret the impact of management practices on the sustainability of the animal, soil, vegetation and water resource, and the economic viability of the business.

In order to win the approval of sceptical environmentalists we need to ensure that the state of the environment is monitored. However, it will be more important to gauge trends in environmental effects rather than to decide arbitrarily the absolute values of sustainability. A practical "farmer friendly" scale of indicators has been developed by farmers to allow assessment of the impact of management over time.

The scales are on a 0 to 20 scale $(0$ non sustainable, 20 sustainable) and verbal descriptions of the resource state are placed at points along the scale.

Farmers in the study groups have ranked their farms as they are seen at this time, and identified where they would aim to be on the scale in three years' time.
We have used as the key indicators the major goals that farmers identified would be used to realise sustainable farming.

As examples two of the scales are:

\section{- Productive vegetation}

- Clean water

The sensitivity of farmers to sustainability issues was obvious in our initial workshops when we attempted to define "sustainability". Not until farmers felt comfortable that the developed ideas sat within their definitions were the barriers broken down. Our experience has shown that in order to gain farmer confidence, personal involvement and understanding will be essential.

\section{In summary}

We have taken up the underlying philosophy of farmers that good stewardship of their land to protect the resource for future generations is paramount. We have built upon this caretaker role and their fiercely independent philosophy in a manner in which farmers can accept to the concept of sustainable farming.

Farmers have: Defined sustainable farming.

Identified the management practices (the key components that lead to indicators) Listed the indicators that lead to sustainability.

We have now compiled a series of fact sheets, published in Federated Farmers Sustainable Agricultural Manual. These point out the environmental benefit that

Productive vegetation

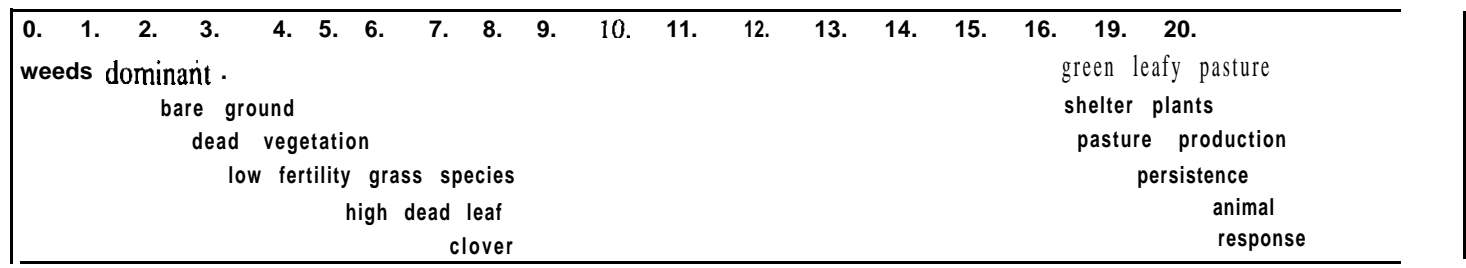

Clean water

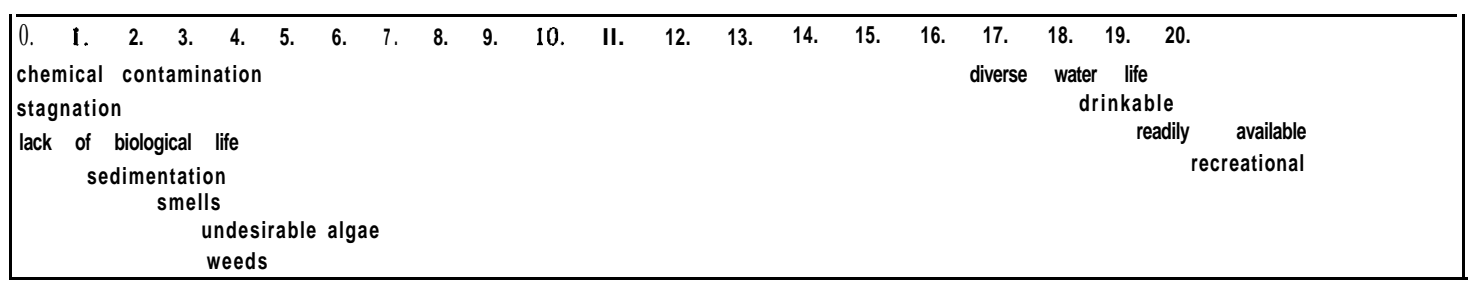


can be expected from following a series of management practices. We can harness New Zealand's unique position as clean, green - "sustainable" - enhancing our market access. The publication sets out to be an information resource and is to act as a guide, a reminder and a stimulator.

Partnerships have been formed along the way with AgResearch, Environment Waikato, and MAF who have all participated in this stage of the project providing backup support when required.

Farmers now have the tools from which to build some robust monitoring techniques which can lead to large-scale farmer acceptance, and thus benefit farmers' economically and address the long-term environmental demands that we will increasingly face.

We have an opportunity to seize the initiative and promote information on sustainable farming in a meaningful and practical way.

\section{ACKNOWLEDGEMENTS}

Federated Farmers wishes to acknowledge the assistance of AgResearch, Environment Waikato, MAFPOL and the Foundation of Science Research and Technology.

\section{REFERENCES}

Grey, H. 1995. Pastoral guidelines Hawke's Bay Regional Council.

Parminter, T.G.; Wedderburn, M.E.; Carter, J.C. 1993. Waikato Regional Workshops on Sustainable Agriculture: A Partnership Approach by Federated Farmers, AgResearch and Environment Waikato. AgResearch Public Document. 